\title{
Optimization of Two-stage Pretreatment from Soybean Hull for Efficient Glucose Recovery*1
}

\author{
Ji Young Jung*2, Myung Suk Choi*2, and Jae-Kyung Yang*2†
}

\begin{abstract}
Soybean hull is an attractive feedstock for glucose production. To increase the glucose conversion in acid hydrolysis, a pretreatment method combined steam explosion with alkali pretreatment for soybean hull was studied. For first step pretreatment, steam explosion conditions ( $\log R o$ 2.45) were optimized to obtain maximum solid recovery and cellulose content. In the second step pretreatment, the conditions for potassium hydroxide pretreatment of steam exploded soybean hull were optimized by using RSM (response surface methodology). The optimum conditions for minimum lignin content were determined to be $0.6 \%$ potassium hydroxide concentration, $70^{\circ} \mathrm{C}$ reaction temperature and 198 min reaction time. The predicted lignin content was $2.2 \%$ at the optimum conditions. Experimental verification of the optimum conditions gave the lignin content in similar value with the estimated value of the model. Finally, glucose conversion of pretreated soybean hull using acid hydrolysis resulted in $97.1 \pm 0.4 \%$. This research of two-step pretreatment was a promising method for increasing the glucose conversion in the cellulose-to-glucose process.
\end{abstract}

Keywords : Soybean hull, pretreatment, steam explosion, potassium hydroxide, response surface methodology

\section{INTRODUCTION}

Agricultural residues such as corn stover, oat hull, sugar bagasse, rice straw and wheat straw are important starting materials (feedstocks) for development of a cellulosic biomass ethanol industry because they are inexpensive sources of complex carbohydrates that can be used to produce ethanol (Gruno et al., 2004).

Soybean hulls are an agricultural residue produced during processing of soybean oil. Soy bean hulls represent the major by-product of soybean processing industry and constitute about $8 \%$ of the whole seed (Gnanasambandan and Proctor, 1999). Considered a waste product from the production of soy oil, soybean meal, and other high protein products, soybean hulls are typically sold as it is or as compressed pellets and fed to cows (Blasi et al., 2000).

Pretreatment of lignocelluloses with saturated steam (i.e. steam explosion) or hot water (autohydrolysis), or with addition of small amounts

*1 Received on January 16, 2012; accepted on March 23, 2012

*2 Division of Environmental Forest Science and Institute of Agriculture \& Life Science, Gyeongsang National University, Jinju 660-701, Korea

† Corresponding author : Jae-Kyung Yang (e-mail: jkyang@gnu.ac.kr) 
of acids, has been widely studied to weaken the lignocellulosic structure (Cara et al., 2008; Chen and Liu, 2007). One of the most promising pretreatments appears to be steam explosion. This process was originally developed by Mason in 1925 and has been extensively used in the manufacture of hardboard (Spalt, 1977).

This steam explosion not only causes a physical change in the cellulosic biomass (Bungay et al., 1983; Dekker and Wallis, 1983), but also causes considerable chemical changes. Studies on the steam explosion of lignocelluloses have mainly focused on lignin fraction and cellulose fraction. However, conditions known to promote lignin depolymerisation also cause degradation of hemicellulose sugars into furfural, 5-hydroxymethyl furfural (HMF) and carboxylic acid. These degradation products inhibit downstream processing (Kim and Lee, 2006; Thomsen et al., 2009). To circumvent this drawback, two-stage pretreatments are generally considered to be the best option: a first step is performed at low severity to hydrolys the hemicelluloses and the second step, where the solid material from the first step is pretreated again, at higher severity. This approach can result in higher sugar yields than one-step pretreatment and has been proposed in the literature several times (Nguyen et al., 2000; Söderström et al., 2002; Monavari et al., 2009). Various studies have reported that cellulose hydrolysis improves with increasing lignin removal, although differences have been reported in the degree of lignin removal needed (Gharpuray et al., 1983; Gould, 1984; Grohmann et al., 1986; Yang et al., 2002). Alkaline treatment has been successfully developed for lignocellulose pretreatment, and the agents are effective for hemicellulose and lignin removal (Carrillo et al., 2005; Zhu et al., 2006). The mechanism of alkaline treatment is believed to be saponification of intermolecular ester bonds crosslinking xylan hemicelluloses and other components, for example, lignin and other hemicellulose. The porosity of the lignocellulosic materials increases with the removal of the crosslinks (Feist et al., 1969). Chlorine treatment has been conventional for many years to delignify and bleach wood pulp by the use of various chlorination procedures.

Optimization of pretreatment conditions for lignocellulosic biomass is one of the most important stages in the development of an efficient and economic pretreatment method. The traditional 'one-factor-at-a-time approach' is time consuming and moreover the interactions between independent variables are not considered (Karunanithy and Muthukumarappan, 2011). Recently, RSM has been successfully applied to biomass pretreatment by many researchers $(\mathrm{Ca}-$ nettieri et al., 2007; Kim and Mazza, 2008; Lu et al., 2007; Neureiter et al., 2002; Rahman et al., 2007; Xin and Saka, 2008).

Acid hydrolysis is a fast and easy method to perform but it is hampered by non-selectivity and byproduct formation (Gray et al., 2006; Zhu et al., 2011)

During acid hydrolysis of lignocellulosics, in addition to the sugars, aliphatic acids (acetic, formic and levulinic acid), furan derivatives, furfural and 5-hydroxymethylfurfural (HMF), and phenolic compounds are formed (Larsson et al., 1999). These compounds are known to affect ethanol fermentation performance ( $\mathrm{Li}$ and Chen, 2008; Mansfield et al., 1999).

The aim of the present work was to evaluate the effciency of two-step pretreatment (steam explosion and chemical pretreatment) for the removal of hemicellulose and lignin from soybean hull and response surface methodology with central composite design (CCD) adopted to optimize the potassium hydroxide pretreatment parameters for minimum lignin content of steam exploded soybean hull. 


\section{MATERIALS and METHODS}

\subsection{Raw Material}

The biomass used in this study was shredded soybean hull, obtained at Korea Research Institute of Chemical Technology in the city of Daejeon, Korea.

The soybean hull was hammer-milled to a particle size of $-20 \mathrm{mesh} /+80 \mathrm{mesh}$, then stored in sealed plastic bags at $4^{\circ} \mathrm{C}$ until used.

\subsection{Characterization of Soybean hull}

The chemical composition of soybean hull and its pretreated one were determined by the National Renewable Energy Laboratory (NREL) using Standard Biomass Analytical Procedures (Sluiter et al., 2005). The glucose was determined using high performance liquid chromatography (HPLC). The HPLC (Agilent, USA) system was equipped with a Aminex HPX-87P column (Bio-Rad, Hercules, CA), a guard column, an automated sampler, a gradient pump, and a refractive index detector. The mobile phase was deionized water at a flow rate of 0.6 $\mathrm{m} \ell \mathrm{min}^{-1}$ at $85^{\circ} \mathrm{C}$. Prior to HPLC injection, all samples were neutralized with calcium carbonate, and filtered through $0.2 \mu \mathrm{m}$ syringe filters.

\subsection{Pretreatment of Soybean Hull}

\subsubsection{Steam Explosion Pretreatment}

Steam explosion pretreatment, which is used as a physicochemical pretreatment, is carried out in a batch pilot unit equipped with a $1 \ell$ reaction vessel. The "severity parameter : $R O$ " is used to map the destruction, desegregation, and depolymerization of soybean hull $R o$ is calculated using the following equation, Eq. (1) (Fernández-Bolaños et al., 1999) :

$$
R o=\left\{t^{*} \exp [(T-100) / 14.5]\right\}
$$

Where $T$ is the temperature $\left({ }^{\circ} \mathrm{C}\right)$ and $t$ is the time (min). A steam temperature of $183{ }^{\circ} \mathrm{C}$ and pretreatment time of 5,10 and 15 min were applied to realize a severity parameter value, which ensured a significant reduction of DP (degree of polymerization) with the lowest degradation and produced a material more suitable for hydrolysis (De Bari et al., 2002). After the saturated steam exposure, a ball valve at the bottom of the reactor was opened suddenly to bring the reactor rapidly to atmospheric pressure. This yielded the product, containing liquid and solid materials (Take et al., 2006). The steam exploded material was recovered in a cyclone and after cooling to about $40^{\circ} \mathrm{C}$ filtered for solid recovery. The solid fraction was water-washed and used for chemical pretreatment.

\subsubsection{Chemical Pretreatment}

Different chemical solutions (sodium hydroxide, potassium hydroxide, sodium hypochlorite and sodium chlorite) were used to determine the optimum chemical solution for delignification. We added $100 \mathrm{~m} \ell$ of $1 \%(\mathrm{w} / \mathrm{v})$ of $\mathrm{NaOH}, \mathrm{KOH}$, $\mathrm{NaClO}$ and $\mathrm{NaClO}_{2}$ to $300 \mathrm{~m} \ell$ Erlenmeyer flasks at a steam exploded sample loading of $1 \%$ $(\mathrm{w} / \mathrm{v})$ in an shaking incubator (IS-97 IR from Jeio-Tech Co., Korea) at the room temperature and $100 \mathrm{rpm}$ for 3 hours. After the pretreatment, the sample was washed with distilled water several times, and used for chemical composition.

\subsection{Design of Experiment}

Central Composite Design (CCD) and response surface methodology (RSM) were used to design a systematic experimental method (Ma et al., 2009; Tan et al., 2011) to optimize the 
Optimization of Two-stage Pretreatment from Soybean Hull for Efficient Glucose Recovery

Table 1. Coded and decoded values for each variable of the central composite design

\begin{tabular}{cccc}
\hline $\begin{array}{c}\text { Coded levels of } \\
\text { experimental factors }\end{array}$ & $\begin{array}{c}\mathrm{X}(1): \\
\text { Potassium hydroxide } \\
\text { concentration }(\%)\end{array}$ & $\begin{array}{c}\mathrm{X}(2): \\
\text { Reaction temperature } \\
\left({ }^{\circ} \mathrm{C}\right)\end{array}$ & $\begin{array}{c}\mathrm{X}(3): \\
\text { Reaction time } \\
(\mathrm{min})\end{array}$ \\
\hline \hline-1.414 & 0.5 & 30 & 120 \\
-1 & 0.75 & 45 & 150 \\
0 & 1 & 60 & 180 \\
1 & 1.25 & 75 & 210 \\
1.414 & 1.5 & 90 & 240 \\
\hline
\end{tabular}

Table 2. The central composite design for the response surface methodology

\begin{tabular}{cccc}
\hline \multirow{2}{*}{ Run } & \multicolumn{3}{c}{ Experimental design } \\
\cline { 2 - 4 } & $\mathrm{X}(1)^{1)}$ & $\mathrm{X}(2)^{2)}$ & $\mathrm{X}(3)^{3)}$ \\
\hline \hline 1 & 1 & -1 & -1 \\
2 & 0 & 0 & 0 \\
3 & -1 & 1 & -1 \\
4 & -1 & 1 & 1 \\
5 & 1 & 1 & -1 \\
6 & -1 & -1 & 1 \\
7 & 0 & 0 & -1.414 \\
8 & -1.414 & 0 & 0 \\
9 & 0 & 0 & 0 \\
10 & 0 & -1.414 & 0 \\
11 & 1 & 1 & 1 \\
12 & 0 & 1.414 & 0 \\
13 & 0 & 0 & 1.414 \\
14 & -1 & -1 & -1 \\
15 & 1.414 & 0 & 0 \\
16 & 1 & -1 & 1 \\
17 & 0 & 0 & 0 \\
\hline
\end{tabular}

1) Coded value of potassium hydroxide concentration.

2) Coded value of reaction temperature.

3) Coded value of reaction time. potassium hydroxide pretreatment of soybean hull. Three independent variables studied were potassium hydroxide concentration (X1), reaction temperature (X2), and reaction time (X3). The range and levels of the independent variables studied were selected based on a preliminary study and was listed in Table 1 . All variables at zero level constitute to the center points and the combination of each of the variables at either its lowest $(-1.414)$ or highest $(+1.414)$ level with the other variables at zero level constitute the axial points. Table 2 represents the experiment matrix and the experimental response (yield, cellulose content and lignin content).

\subsection{Statistical Analysis}

RSREG (SAS : statistial analysis system, SAS institute U.S.A) was used for regression analysis and analysis of variance (ANOVA). By using RSM, the experimental response obtained was analyzed with the following second-order polynomial, Eq. (2) :

$$
\begin{aligned}
\mathrm{Y}= & \beta_{0}+\beta_{1} \mathrm{X}(1)+\beta_{2} \mathrm{X}(2)+\beta_{3} \mathrm{X}(3)+\beta_{11} \mathrm{X}(1)^{2} \\
& +\beta_{12} \mathrm{X}(1) \mathrm{X}(2)+\beta_{22} \mathrm{X}(2)^{2}+\beta_{13} \mathrm{X}(1) \mathrm{X}(3) \\
& +\beta_{23} \mathrm{X}(2) \mathrm{X}(3)+\beta_{33} \mathrm{X}(3)^{2}
\end{aligned}
$$

Response surfaces and contour plots were de- 
veloped using the fitted quadratic polynomial equation obtained from regression analysis, holding one of the independent variables at a constant value corresponding to the stationary point and changing the other two variables.

\subsection{Acid Hydrolysis}

Acid hydrolysis was performed according to the method originally described by Ritter et al (Ritter et al., 1932). In short, $300 \mathrm{mg}$ of material was weighted into a hydrolysis tube, $3 \mathrm{ml}$ of $72 \%(\mathrm{w} / \mathrm{w})$ sulfuric acid was added and samples were primary hydrolyzed at $30^{\circ} \mathrm{C}$ in water bath for 30, 60 and $120 \mathrm{~min}$. The samples were transferred into a $100 \mathrm{~m} \ell$ volumetric flask with addition of $84 \mathrm{~m} \ell$ distilled water. Flasks were sealed with aluminum foil and autoclaved for 30,60 and $90 \mathrm{~min}$ at $120^{\circ} \mathrm{C}$ (secondary hydrolysis). After hydrolysis, the samples were cooled and filtered with $0.2 \mu \mathrm{m}$ filters. Untreated (raw) soybean hull was also prepared for direct acid hydrolysis without pre-treatment as a control set. The glucose was determined using high performance liquid chromatography (HPLC). The percent glucose conversion after acid hydrolysis was calculated as Eq. (3) :

$$
\begin{aligned}
& \% \text { Glucose conversion } \\
& =\frac{\text { glucose in acid hydrolysate }(\%)}{\text { glucose in pretreated sample }(\%)} \times 100
\end{aligned}
$$

\section{RESULTS and DISCUSSION}

\subsection{Chemical Composition of Soybean Hull}

The chemical composition of soybean hull varies according to its growth location, season, harvesting method, and analysis procedure. The
Table 3. Chemical composition of soybean hull ${ }^{1)}$

\begin{tabular}{cc}
\hline Composition & \% Dry weight \\
\hline \hline Extractives & $6.8 \pm 0.5^{2)}$ \\
Cellulose as glucose $^{2}$ & $50.8 \pm 0.4$ \\
Hemicellulose $^{3)}$ as & 14.5 \\
Xylose & - \\
Galactose & - \\
Arabinose & 14.5 \\
Mannose & - \\
Acid insoluble lignin & $10.4 \pm 0.5$ \\
Acid soluble lignin & $1.1 \pm 0.0$ \\
Ash & $4.1 \pm 0.1$ \\
Protein & 11.0
\end{tabular}

1) Data in the table was based on oven dry samples.

2) Mean values of triplicate samples with standard deviations.

3) Hemicellulose : xylose + galactose + arabinose + mannose.

chemical composition of the soybean hull used in this study was presented in Table 3. Fifty one percent of the dry raw material consisted of cellulose that could be used for glucose production. Hemicellulosic sugars account for 14.5\% of raw material with arabinose as the main hemicellulosic sugar. Carbohydrate content (65.3\%) are higher than that of other agricultural residue (rice straw, wheat straw and corn stover) (Ma et al., 2009; Kabel et al., 2007; Kim et al., 2003). In order to obtain the high purity glucose, the pretreatment step should improve the lignin and hemicellulose removal while avoiding degradation of cellulose. Efficient pretreatment is necessary in order to achieve an economically feasible production process (McMillan, 1996).

\subsection{Steam Explosion for Physical Pretreatment}

Table 4 shows the solid recovery (solids re 
Optimization of Two-stage Pretreatment from Soybean Hull for Efficient Glucose Recovery

Table 4. Solid recovery and main components of solid resulting from steam explosion pretreatment at different severity log $R_{0}$ in soybean hull ${ }^{1)}$

\begin{tabular}{ccccc}
\hline \multirow{2}{*}{ Severity $\log$ Ro } & Solid recovery, \% & \multicolumn{3}{c}{ Composition, \% (g) } \\
\cline { 3 - 5 } & & Cellulose, \% $(\mathrm{g})$ & Arabinose, \% (g) & \multicolumn{1}{c}{ AIL $^{3)}, \%(\mathrm{~g})$} \\
\hline \hline 2.45 & $82.5 \pm 1.4$ & $46.0(38.0) \pm 0.6$ & $-2)$ & $10.6(8.7) \pm 0.5$ \\
3.15 & $71.3 \pm 0.8$ & $46.3(33.0) \pm 0.3$ & - & $9.5(6.8) \pm 0.3$ \\
3.40 & $70.8 \pm 0.9$ & $45.3(32.1) \pm 0.3$ & - & $5.6(4.0) \pm 0.4$ \\
\hline
\end{tabular}

1) Data was expressed in parentheses as a percentage based on dry weight of raw material.

2) Not detected.

3) Acid insoluble lignin.

Table 5. Solid recovery, cellulose content and lignin content of steam exploded soybean hull followed $1 \% \mathrm{NaOH}, 1 \% \mathrm{KOH}, 1 \% \mathrm{NaClO}$ and $1 \% \mathrm{NaClO}_{2}$, respectively

\begin{tabular}{cccc}
\hline Pretreatment & Solid recovery $(\mathrm{g})$ & Cellulose content $(\mathrm{g})$ & Lignin content $(\mathrm{g})$ \\
\hline \hline Raw material ${ }^{1)}$ & 100 & $50.8 \pm 0.4$ & $10.4 \pm 0.5$ \\
Severity $\log$ Ro $2.45^{2)}$ & $82.5 \pm 1.4$ & $37.9 \pm 0.6$ & $8.7 \pm 0.5$ \\
Severity $\log$ Ro $2.45-1 \% \mathrm{NaOH}$ & $68.6 \pm 0.2$ & $27.6 \pm 0.4$ & $3.3 \pm 0.5$ \\
Severity $\log$ Ro $2.45-1 \% \mathrm{KOH}$ & $73.0 \pm 0.3$ & $29.5 \pm 0.2$ & $2.9 \pm 0.4$ \\
Severity $\log$ Ro $2.45-1 \% \mathrm{NaClO}$ & $63.9 \pm 0.2$ & $25.5 \pm 0.5$ & $4.9 \pm 0.2$ \\
Severity $\log$ Ro $2.45-1 \% \mathrm{NaClO} 2$ & $72.2 \pm 0.1$ & $26.0 \pm 0.1$ & $5.3 \pm 0.2$ \\
\hline
\end{tabular}

1) Untreated.

2) Steam explosion condition.

maining after pretreatment divided by original oven-dried weight) and the composition of solid resulting from steam explosion pretreatment at the different severity $\log R o$. Solid recovery was $70.8 \sim 82.5 \%$ and was comparable to those obtained at similar severity $\log R o$ value for sugar cane bagasse (78 to $99 \%$ ) (Kaar et al., 1998), red oak chips (74 to 83\%) (Ibrahim, 1998) and sunflower stalks (55 to 65\%) (Ruiz et al., 2008). As expected, a decrease of solid recovery was detected as the severity $\log R o$ increased. The maximum solid loss (approximately $30 \%$ ) was appeared at severity $\log R o$ 3.40. The solid loss was due to the production of volatile compounds which were entrained in the steam. In addition, the solid loss may also happen during steam pretreatment because of the deposition of fiber on the walls of the cyclone and connecting piping between the reactor vessel and the cyclone (Jeoh, 1998). The AIL content decreased from 8.7 to $4.0 \mathrm{~g}$ and hemicellulose content completely removed at severity $\log R o \quad 2.45 \sim$ severity $\log R o$ 3.40. The cellulose content of the steam exploded samples varied from 32.1 to $37.9 \mathrm{~g}$ of the original cellulose content $(50.8 \mathrm{~g})$ of the raw feedstock. In the biomass feedstock, cellulose is the main reservoir of glucose, the desired fermentation substrate for bioenergy source (Jeoh, 1998). In optimizing steam explosion pretreatment condi- 
tions for chemical pretreatment (lignin removal), cellulose losses is an important considerable factor.

\subsection{Chemical Pretreatment for Deli- gnification}

According to the results of steam explosion pretreatment (Table 4), solid fraction of severity $\log$ Ro 2.45 was chosen for the subsequent chemical pretreatment (the maximum solid recovery (82.5\%) was attained at $\log R o \quad 2.45)$. The cellulose content and lignin content change of soybean hull were important indices for the effectiveness of its pretreatment. The solid recovery, cellulose content and lignin content were shown in Table 5. Results show that when compared with the untreated materials, both alkaline and chlorine pretreatment decrease cellulose content and lignin content, ranging from 25.5 to $29.5 \mathrm{~g}$ and 2.9 to $5.3 \mathrm{~g}$, respectively. The best procedure for efficiently removing lignin from the steam exploded soybean hull was the combination with alkali treatment. The alkali treatment was originally suggested by Feist et al. (Feist et al., 1970) as a way to partially solubilize lignin and improve the digestibility of wood substrate. Subsequently, it was also used to efficiently remove lignin from steam-exploded hardwood residues in the literature (Ramos et al., 1993). The minimum lignin content $(2.9 \mathrm{~g})$ was attained at severity $\log$ Ro 2.45 $1 \% \mathrm{KOH}$.

\subsection{Regression Analysis for the Po- tassium Hydroxide Pretreatment}

The design of this experiment together with the yield, cellulose content and lignin content which were taken as the dependent variables or responses, was given in Table 6. The yield from the steam exploded - $\mathrm{KOH}$ treated soybean hull
Table 6. The central composite design for the response surface methodology

\begin{tabular}{ccccccc}
\hline & \multicolumn{2}{c}{ Experimental design } & \multicolumn{3}{c}{ Dependent variables } \\
\cline { 2 - 7 } Run & X $(1)^{1)}$ & $\mathrm{X}(2)^{2)} \mathrm{X}(3)^{3)}$ & $\begin{array}{c}\text { Yield } \\
(\%)\end{array}$ & $\begin{array}{c}\text { Cellulose } \\
\text { content } \\
(\%)\end{array}$ & $\begin{array}{c}\text { Lignin } \\
\text { content } \\
(\%)\end{array}$ \\
\hline \hline 1 & 1 & -1 & -1 & 79.8 & 50.4 & 5.3 \\
2 & 0 & 0 & 0 & 78.0 & 61.4 & 3.4 \\
3 & -1 & 1 & -1 & 74.7 & 65.6 & 3.1 \\
4 & -1 & 1 & 1 & 64.9 & 75.8 & 3.1 \\
5 & 1 & 1 & -1 & 71.0 & 71.3 & 2.4 \\
6 & -1 & -1 & 1 & 78.9 & 48.6 & 3.0 \\
7 & 0 & 0 & -1.414 & 80.1 & 59.5 & 3.4 \\
8 & -1.414 & 0 & 0 & 79.5 & 59.8 & 5.5 \\
9 & 0 & 0 & 0 & 78.0 & 61.4 & 3.4 \\
10 & 0 & -1.414 & 0 & 87.9 & 45.4 & 6.8 \\
11 & 1 & 1 & 1 & 65.7 & 78.3 & 2.4 \\
12 & 0 & 1.414 & 0 & 47.1 & 93.0 & 2.6 \\
13 & 0 & 0 & 1.414 & 75.9 & 63.5 & 3.1 \\
14 & -1 & -1 & -1 & 81.0 & 48.8 & 5.4 \\
15 & 1.414 & 0 & 0 & 77.6 & 62.3 & 3.3 \\
16 & 1 & -1 & 1 & 78.3 & 55.4 & 4.1 \\
17 & 0 & 0 & 0 & 78.0 & 61.4 & 3.4 \\
\hline
\end{tabular}

1) Coded value of potassium hydroxide concentration.

2) Coded value of reaction temperature.

3) Coded value of reaction time.

ranged from 47.1 to $87.9 \%$, cellulose content ranged from 45.4 to $93.0 \%$, lignin content ranged from 2.4 to $6.8 \%$.

To test the significance of the developed model, analysis of variance (ANOVA) was performed and the results were presented in Table 7. ANOVA was performed to evaluate the effects of the variables and their possible interactions. The coefficients of the full model were evaluated using regression analysis, and their significance was tested. Insignificant coefficie- 
Optimization of Two-stage Pretreatment from Soybean Hull for Efficient Glucose Recovery

Table 7. ANOVA results for the response of the yield, cellulose content and lignin content

\begin{tabular}{cccccc}
\hline Factors & Sum of squares & Mean squares & $F$-value & $\begin{array}{c}P \text {-value } \\
\text { (Prob > F) }\end{array}$ & \\
\hline \hline Yield & & & & & \\
X(1) & 65.844590 & 16.461147 & 1.67 & 0.2592 & \\
X(2) & 829.004853 & 207.251213 & 21.05 & $0.0005^{* 4)}$ & Significant \\
X(3) & 7.959758 & 1.989864 & 0.20 & 0.9293 & \\
Cellulose content & & & & & \\
X(1) & 75.529612 & 18.882403 & 3.11 & 0.0907 & \\
X(2) & 2182.851156 & 545.712789 & 89.90 & $<0.0001^{*}$ & Significant \\
X(3) & 29.878954 & 7.469739 & 1.23 & 0.3792 & \\
Lignin content & & & & & \\
X(1) & 2.955223 & 0.738806 & 2.17 & 0.1740 & \\
X(2) & 18.645223 & 4.661306 & 13.72 & $0.0020^{*}$ & Significant \\
X(3) & 3.412592 & 0.853148 & 2.51 & 0.1359 & \\
\hline
\end{tabular}

1) Coded value of potassium hydroxide concentration.

2) Coded value of reaction temperature.

3) Coded value of reaction time.

4) $*:<0.005$

nts were excluded from the model. A model was considered significant if its $p$-value (also known as the 'Prob $>\mathrm{F}$ ' value) is lower than 0.05 , indicating only a $5 \%$ chance that a 'Model $F$-value' could occur because of noise. The "Prob $>$ F" values were also used to evaluate the significance of the effects of each linear, quadratic and interaction term on the response. In addition, the 'Prob $>F$ ' values for each model term suggest that $\mathrm{X}(2)$ were the model terms that have significant effects on the yield, cellulose content and lignin content. The correlation value, $\mathrm{R}^{2}$ for the model of lignin content was 0.9053 . The high $R^{2}$ value specifies that the model obtained will be able to give a convincingly good estimate for response of the system within the range studied.

Fig. 1 represents the three-dimensional response surface plot of lignin content at a potas-

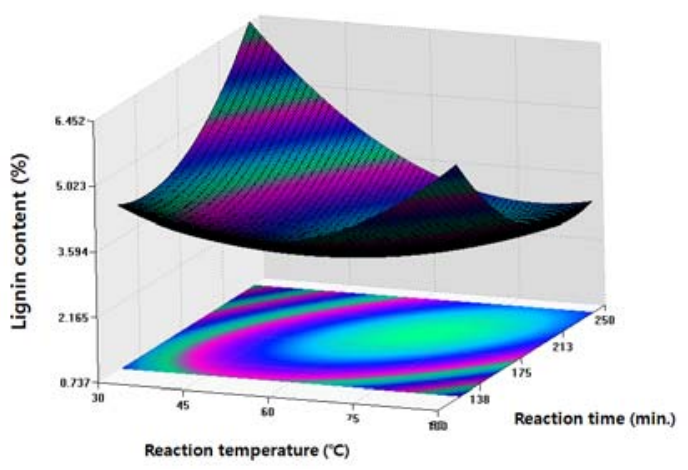

Fig. 1. Three-dimensional response surface plot of lignin content : effect of reaction time and reaction temperature at a potassium hydroxide concentration of $0.6 \%$.

sium hydroxide concentration of $0.6 \%$ to investigate the interactive effect of reaction time and reaction temperature. At different reaction time, the lignin content reaches a minimum value at 
Table 8. Glucose conversion of steam exploded ${ }^{1)}$ - $\mathrm{KOH}$ treated ${ }^{2)}$ soybean hull subjected to different periods of primary and secondary hydrolysis

\begin{tabular}{ccc}
\hline $\begin{array}{c}\text { Primary hydrolysis at } 30^{\circ} \mathrm{C} \text {, with } \\
72 \% \text { acid (min.) }\end{array}$ & $\begin{array}{c}\text { Secondary hydrolysis at } 121^{\circ} \mathrm{C}, \\
\text { with } 4 \% \text { acid (min.) }\end{array}$ & Glucose conversion $^{3)}(\%)$ \\
\hline \hline & 30 & $92.6 \pm 0.1 \mathrm{c}^{4)}$ \\
30 & 60 & $88.4 \pm 0.2 \mathrm{~d}$ \\
& 90 & $89.7 \pm 0.1 \mathrm{~d}$ \\
60 & 30 & $96.5 \pm 0.2 \mathrm{ab}$ \\
& 60 & $96.1 \pm 0.2 \mathrm{ab}$ \\
& 90 & $97.1 \pm 0.3 \mathrm{a}$ \\
90 & 30 & $96.5 \pm 0.1 \mathrm{ab}$ \\
& 60 & $94.5 \pm 0.2 \mathrm{bc}$ \\
& 90 & $95.8 \pm 0.2 \mathrm{ab}$ \\
\hline
\end{tabular}

1) Severity $\log (R o) 2.45$

2) Potassium hydroxide concentration : $0.6 \%$

Reaction temperature : $70^{\circ} \mathrm{C}$

Reaction time : $198 \mathrm{~min}$.

3) The value was calculated based on the pretreated material.

4) The statistical significance of the results was assessed by Duncan's $t$-test $(p \leqq 0.05$ )

approximate $70^{\circ} \mathrm{C}$ and slightly increases above that value. This study has revealed that potassium hydroxide pretreatment at a moderate temperature around $70^{\circ} \mathrm{C}$ minimized lignin content within the range $65 \sim 75^{\circ} \mathrm{C}$ and reaction time from 175 to $213 \mathrm{~min}$.

\subsection{Optimization of Delignification}

The conditions of the system were optimized using the CCD based on the model obtained and the input criteria. The optimization of delignification was carried out based on the three variables (potassium hydroxide concentration, reaction temperature and reaction time) which were in the range of experimental runs.

A regression analysis was performed to fit the response function and predict the outcome of lignin content with a simple equation. The model was expressed by Eq. (4), which uses their values.

$$
\begin{aligned}
\text { Lignin content }= & +26.134783 \\
& -0.08413 \times \text { Time } \\
& -0.228841 \times \text { Temp. } \\
& -10.180435 \times \text { Conc. } \\
& +0.000261 \times \text { Time }^{2} \\
& -0.000667 \times \text { Time } \times \text { Temp. } \\
& +0.001379 \times \text { Temp. }^{2} \\
& +0.02 \times \text { Time } \times \text { Conc. } \\
& +0.12 \times \text { Temp. } \times \text { Conc. } \\
& -0.83478 \times \text { Conc. }^{2}
\end{aligned}
$$

The software predicted that optimized conditions for lignin content were obtained when the potassium hydroxide concentration, reaction temperature and reaction time were at $0.6 \%$, $70^{\circ} \mathrm{C}$ and $198 \mathrm{~min}$ respectively, giving a predicted lignin content of $2.2 \%$ (Eq. 3). The pre- 
dicted optimum yield was verified by carrying out experimental runs using the suggested optimum process conditions. The experimental run gave an actual optimum lignin content of $1.2 \%$, in good agreement with the value calculated using the model.

\subsection{Acid Hydrolysis}

Glucose conversion of the steam exploded $\mathrm{KOH}$ treated soybean hull by acid hydrolysis at different reaction time were shown in Table 8. Among the different reaction time, the maximum glucose conversion (97.1\%) was obtained by $60 \mathrm{~min}$ primary hydrolysis and $90 \mathrm{~min}$ secondary hydrolysis. No significant difference in glucose conversion was observed when the substrate was treated with $>60$ min primary hydrolysis. Increasing the acid hydrolysis reaction time beyond 120 min primary hydrolysis, resulted in a decrease in the final glucose conversion. This may be due to the degradation of carbohydrates at severe conditions.

The acid hydrolysis of different pretreated soybean hull to glucose conversion was present in Table 9. The glucose conversion from pretreated soybean hull was higher, compared to raw material under the same acid hydrolysis conditions. The glucose conversion efficiency was increased to $97.1 \%$ in the steam exploded - alkali treated soybean hull.

A significant drawback of the acid hydrolysis process, compared to the enzymatic hydrolysis process, is the formation of inhibitors. The inhibitor compound can be present in the raw material or be produced during the hydrolysis process. They are classified in four major groups: sugar-derived by-products (furfural and hydroxymethylfurfural), aliphatic acids (acetic acid, levulinic acid), lignin degradation products which include a wide range of aromatic and polyaromatic compounds with a variety of substituents, and inhibitors derived from metals or minerals
Table 9. Glucose conversion of different pretreated soybean hull subjected to acid hydrolysis ${ }^{1)}$

\begin{tabular}{cc}
\hline Samples & ${\text { Glucose conversion }(\%)^{2)}}^{2}$ \\
\hline \hline Raw material & $88.8 \pm 0.4$ \\
Steam exploded $^{3)}$ & $91.5 \pm 0.3$ \\
Alkali treated $^{4)}$ & $93.6 \pm 0.2$ \\
Steam exploded $^{3)}$ & $97.1 \pm 0.4$ \\
${\text { - } \text { alkali treated }^{4)}}$
\end{tabular}

1) Acid hydrolysis condition : primary hydrolysis at $30^{\circ} \mathrm{C}$, with $72 \%$ acid and 60 min, secondary hydrolysis at $121^{\circ} \mathrm{C}$, with $4 \%$ acid and $90 \mathrm{~min}$.

2) The value was calculated based on the pretreated material.

3) Severity $\log$ Ro 2.45

4) Potassium hydroxide concentration : $0.6 \%$

Reaction temperature : $70^{\circ} \mathrm{C}$

Reaction time : $198 \mathrm{~min}$.

in wood (Palmqvist and Hanh, 2000). However, two-stage pretreatment avoid the formation of inhibitory products by hemicellulose and lignin removal.

\section{CONCLUSION}

The results obtained in this study suggested that the steam explosion pretreatment of soybean hull followed by alkali treatment is a promising alternative separation process that allow the high purity of cellulose with removal of hemicellulose and lignin. This study showed a combined pretreatment for soybean hull using steam explosion, alkaline and chlorine. The cellulose content of soybean hull was obtained to $29.5 \mathrm{~g}$ using steam explosion (severity $\log R o$ 2.45) combined with potassium hydroxide pretreatment. The conditions for potassium hydroxide pretreatment of steam exploded soybean hull were optimized by using RSM. The major parameter influencing was reaction temperature in yield, cellulose content and lignin content. The 
optimum conditions for minimum lignin content were determined to be $0.6 \%$ potassium hydroxide concentration, $70^{\circ} \mathrm{C}$ reaction temperature and 198 min reaction time. Under these conditions, the predict value of lignin content was $2.2 \%$, and the experimental run gave an actual optimum lignin content of $1.2 \%$. The glucose conversion after two-step pretreatment (steam explosion - $\mathrm{KOH}$ pretreatment) followed by acid hydrolysis reached $97.1 \%$. The two-step pretreatment results in higher glucose conversion than the raw material. Future study will be focused on optimizing this process by considering inhibitor compound, material balance, cost, energy, and environmental factor.

\section{ACKNOWLEDGEMENT}

This study was carried out with the support of "Development of Application Technology using Succinic Acid Derivatives (project No. 100 33530)" provide by Ministry of Knowledge Economy, Republic of Korea.

\section{REFERENCES}

1. Blasi, D. A., J. Drouillard, E. C. Titgemeyer, S. I. Paisley, and M. J. Brouk. 2000. Soybean hulls composition and feed value for beef and dairy cattle. Kansas State Univ Document 00-79-E.

2. Bungay, H., M. Garcia, and B. Foody. 1983. Treatment and characterization of exploded woodfractions, Biotechnology and Bioengineering Symposium 13: $121 \sim 127$.

3. Canettieri, E. V., G. J. M. Rocha, J. A. Carvalho Jr., and J. B. A. Silva. 2007. Optimization of acid hydrolysis from the hemicellulosic fraction of Eucalyptus grandis residue using response surface methodology. Bioresource Technology 98 (2): $422 \sim 428$.

4. Cara, C., E. Ruiz, M. Ballesteros, P. Manzanares, M. J. Negro, and E. Castr. 2008. Production of fuel ethanol from steam-explosion pretreated olive tree. Fuel 87: 692 700 .
5. Carrillo, F., M. J. Lis, X. Colom, M. LopezMesas, and J. Valldeperas. 2005. Effect of alkali pretreatment on cellulase hydrolysis of wheat straw: kinetic study, Process Biochemistry 40: 3360.

6. Chen, H. Z. and L. Y. Liu. 2007. Unpolluted fractionation of wheat straw by steam explosion and ethanol extraction. Bioresource Technology 98(3): $666 \sim 676$.

7. De Bari, I., E. Viola, D. Barisano, M. Cardinale, F. Nanna, F. Zimbardi, G. Cardinale, and G. Braccio. 2002. Ethanol Production at Flask and Pilot Scale from Concentrated Slurries of SteamExploded Aspen, Industrial and Engineering Chemistry Research 41: 1745 1753.

8. Dekker, R. and A. Wallis. 1983. Enzymic saccharification of sugarcane bagasse pretreated by autohydrolysis steam explosion, Biotechnology and Bioengineering 25: 3027 3048.

9. Feist, W. C, A. J. Baker, and H. Tarkow. 1969. Alkali requirements for improving digestibility of hardwoods by rumen micro-organisms. Journal of Animal Science 30: 832 836.

10. Fernández-Bolaños, J., B. Felizón, A. Heredia, R. Guillén, and A. Jiménez. 1999. Bioresource Tech- nology, 68: 121 132.

11. Gharpuray, M. M., Y. H. Lee, and L. T. Fan. 1983. Structural modification of lignocellulosics by pretreatments to enhance enzymatic hydrolysis, Biotechnology and Bioengineering 25: 157 $\sim 172$.

12. Gnanasambandan, R. and A. Proctor. 1999. Preparation of soy hull pectin. Food Chemistry 65: $461 \sim 467$.

13. Gould, J. M. 1984. Alkaline peroxide delignification of agricultural residues to enhance enzymic saccharification. Biotechnology and Bioengineering 26: $46 \sim 52$.

14. Gray, K. A., L. Zhao, and M. Emptage. 2006. Bioethanol. Current Opinion in Chemical Biology 10: $1 \sim 6$.

15. Grohmann, K., R. Torget, and M. Himmel. 1986. Optimization of dilute acid pretreatment of biomass. Biotechnology and Bioengineering Symposium 15: $59 \sim 80$.

16. Gruno, M., P. Vaeljamaee, G. Pettersson, and G. Johansson. 2004. Inhibition of the Trichoderma 
Optimization of Two-stage Pretreatment from Soybean Hull for Efficient Glucose Recovery

reesei cellulases by cellobiose is strongly dependent on the nature of the substrate. Biotechnology and Bioengineering 86: 503 511.

17. Ibrahim M. 1998. Clean fractionation of biomass-steam explosion and extraction. MS Thesis, Virginia Polytechnic Institute and State University, Blacksburg, VA.

18. Jeoh, T. 1998. Steam explosion pretreatment of cotton gin waste for fuel ethanol production. Master's thesis, Virginia Tech. University, VA.

19. Kaar, W. E., C. V. Gutierrez, and C. M. Kinoshita. 1998. Steam explosion of sugarcane bagasse as a pretreatment for conversion to ethanol, Biomass and Bioenergy 14(3): 277 287.

20. Kabel, M. A., G. Bos, A. G. J J. Zeevalking, and H. A. Voragen. 2007. Schols Effect of pretreatment severity on xylan solubility and enzymatic breakdown of the remaining cellulose from wheat straw, Bioresource Technology 98: 2034 2042.

21. Karunanithy, C. and K. Muthukumarappan. 2011. Optimization of switchgrass and extruder parameters for enzymatic hydrolysis using response surface methodology. Industrial Crop and Products 33: $188 \sim 199$.

22. Kim, J. W. and G. Mazza. 2008. Optimization of phosphoric acid catalyzed fractionation and enzymatic digestibility of flax shives. Industrial Crop and Products 28(3): 346 355.

23. Kim, T. H., J. S. Kim, C. Sun woo, and Y. Y. Lee. 2003. Pretreatment of corn stover by aqueous ammonia, Bioresource Technology 90: 39 47.

24. Kim, T. H. and Y. Y. Lee. 2006. Fractionation of corn stover by hot water and aqueous ammonia treatment, Bioresource Technology 97(2): 224 $\sim 232$.

25. Larsson, S., E. Palmqvist, B. Hahn-Hagerdal, C. Tengborg, K. Stenberg, and G. Zacchi. 1999. The generation of fermentation inhibitors during dilute acid hydrolysis of softwood. Enzyme and Microbial Technology 24: 151 159.

26. Li, H. Q. and H. Z. Chen. 2008. Detoxification of steam-exploded corn straw produced by an industrial-scale reactor, Process Biochemistry 43: $1447 \sim 1451$

27. Lu, X. B., Y. M. Zhang, J. Yang, and Y. Liang.
2007. Enzymatic hydrolysis of corn stover after pretreatment with dilute sulfuric acid, Chemical Engineering and Technology 30(7): 938 944.

28. Ma, H., W. W. Liu, X. Chen, Y. J. Wu, and Z. L. Yu. 2009. Enhanced enzymatic saccharification of rice straw by microwave pretreatment. Bioresource Technology 100: 1279 1284.

29. Mansfield, S. D., C. Mooney, and J. N. Saddler, 1999. Substrate and enzyme characteristics that limit cellulose hydrolysis, Biotechnology Progress 15: $804 \sim 816$.

30. McMillan, J. D. 1996. Hemicellulose conversion to ethanol. In: Handbook on Bioethanol: Production and Utilization. Taylor \& Francis, Washington, DC, USA.

31. Monavari, S., M. Gable, and G. Zacchi. 2009. The influence of solid/liquid separation techniques on the sugar yield in two-step dilute acid hydrolysis of softwood followed by enzymatic hydrolysis. Biotechnology for Biofuels 2: 1 9.

32. Neureiter, M., H. Danner, C. Thomasser, B. Saidi, and R. Braun. 2002. Dilute acid hydrolysis of sugarcane bagasse at varying conditions. Applied Biochemistry and Biotechnology 98: 49 58.

33. Nguyen, Q. A., M. P. Tucker, F. A. Keller, and F. P. Eddy. 2000. Twostage dilute-acid pretreatment of softwoods. Applied Biochemistry and Biotechnology 84 86: 564 576.

34. Palmqvist, E. and H. Hägerdal. 2000. Fer- mentation of lignocellulosic hydrolysates I: inhibition and detoxification. Bioresource Tech- nology 74: $17 \sim 24$.

35. Rahman, S. H. A., J. P. Choudhury, A. L. Ahmad, and A. H. Kamaruddin. 2007. Optimization studies on acid hydrolysis of oil palm empty fruit bunch fiber for production of xylose, Bioresource Technology 98(3), 554 559.

36. Ramos, J. P, C. Breuil, and J. N. Saddler. 1993. The use of enzyme recycling and the influence of sugar accumulation on cellulose hydrolysis by Trichoderma cellulases. Enzyme and Microbial Technology 15: 19 25.

37. Ritter, G., J. R. Seborg, and R. I. Mitchell. 1932. Factors affecting determination of lignin by $72 \%$ sulphuric acid method. Indian Engineering Chemical 4: 202 204. 
38. Ruiz, E., C. Cara, P. Manzanares, M. Ballesteros, and E. Castro. 2008. Evaluation of steam explosion pretreatment for enzymatic hydrolysis of sunflower stalks, Enzyme and Microbial technology 42: $160 \sim 166$.

39. Sluiter, A., B. Hames, R. Ruiz, C. Scarlata, J. Sluiter, and D. Templeton. 2005. National Renewable Energy Laboratory, Standard Biomass Analytical Procedures. Available from: www. nrel.gov/biomass/analytical procedures.html.

40. Söderström, J., L. Pilcher, M. Galbe, and G. Zacchi. 2002. Two-step steam pretreatment of softwood by $\mathrm{SO}_{2}$ impregnation for ethanol production, Applied Microbiology and Biotechnology 2003. Biomass and Bioenergy 24: 475 486

41. Spalt, H. A. 1977. Chemical changes in wood associated with wood fiberboard manufacture. In: Wood technology: chemical aspects, ACS Symp Series, Washington, USA 93: 193 219 .

42. Take, H., Y. Andou, Y. Nakamura, F. Kobayashi, Y. Kurimoto, and M. Kuwahara, 2006. Production of methane gas from Japanese cedar chips pretreated by various delignification methods, Biochemical Engineering Journal 28: 30 35.

43. Tan, H. T., K. T. Lee, and A. R. Mohamed. 2011. Pretreatment of lignocellulosic palm biomass using a solvent-ionic liquid [BMIM] $\mathrm{Cl}$ for glucose recovery: an optimisation study using response surface methodology. Carbohydrate Polymers 83: $1862 \sim 1888$.
44. Tarkow, H. and W. C. Feist. 1969. A Mechanism for Improving the Digestibility of lignocellulosic materials with dilute alkali and liquid $\mathrm{NH}_{3}$ advance chemistry series 95, Washington, DC, American Chemical Society.

45. Thomsen, M. H., A. Thygesen, and A. B. Thomsen. 2009. Identification and characterization of fermentation inhibitors formed during hydrothermal treatment and following SSF of wheat straw. Applied Microbiology and Biotechnology 83(3): $447 \sim 455$.

46. Xin, L. and S. Saka. 2008. Optimization of Japanese beech hydrolysis treated with batch hotcompressed water by response surface methodology. International Journal Agricultural and Biological Engineering 1(2): 39 45.

47. Yang, B., A. Boussaid, S. D. Mansfield, D. J. Gregg, and J. N. Saddler. 2002. Fast and efficient alkaline peroxide treatment to enhance the enzymatic digestibility of steam-exploded softwood substrates, Biotechnology and Bioengineering 77: $678 \sim 684$.

48. Zhu, J. J., Q. Yong, Y. Xu, and S. Yu. 2011. Detoxification of corn stover prehydrolyzate by trialkylamine extraction to improve the ethanol production with Pichia stipitis CBS 5776 . Bioresource Technology 101: 1663 1668.

49. Zhu, S., Y. Wu, Z. Yu, X. Zhang, C. Wang, and F. Yu. 2006. Production of ethanol from microwave-assisted alkali pretreated wheat straw, Process Biochemistry 41: 869 8733. 